\title{
Review
}

\section{Digital Progression Biomarkers as Novel Endpoints in Clinical Trials: A Multistakeholder Perspective}

\author{
Diane Stephenson ${ }^{\mathrm{a}}$, Reham Badawy ${ }^{\mathrm{b}}$, Soania Mathur ${ }^{\mathrm{c}}$, Maria Tome ${ }^{\mathrm{d}}$ and Lynn Rochester ${ }^{\mathrm{e}}$ \\ ${ }^{\mathrm{a}}$ Critical Path Institute, Tucson, AZ, USA \\ ${ }^{\mathrm{b}}$ University of Birmingham, Birmingham, $U K$ \\ ${ }^{\mathrm{c}}$ Unshakeable MD, Toronto, ON, Canada \\ ${ }^{\mathrm{d}}$ European Medicines Agency, Amsterdam, The Netherlands \\ ${ }^{\mathrm{e}}$ Institute of Translational and Clinical Research, Newcastle University, Newcastle, UK
}

Accepted 11 January 2021

Pre-press 11 February 2021

\begin{abstract}
The burden of Parkinson's disease (PD) continues to grow at an unsustainable pace particularly given that it now represents the fastest growing brain disease. Despite seminal discoveries in genetics and pathogenesis, people living with PD oftentimes wait years to obtain an accurate diagnosis and have no way to know their own prognostic fate once they do learn they have the disease. Currently, there is no objective biomarker to measure the onset, progression, and severity of PD along the disease continuum. Without such tools, the effectiveness of any given treatment, experimental or conventional cannot be measured. Such tools are urgently needed now more than ever given the rich number of new candidate therapies in the pipeline. Over the last decade, millions of dollars have been directed to identify biomarkers to inform progression of PD typically using molecular, fluid or imaging modalities. These efforts have produced novel insights in our understanding of PD including mechanistic targets, disease subtypes and imaging biomarkers. While we have learned a lot along the way, implementation of robust disease progression biomarkers as tools for quantifying changes in disease status or severity remains elusive. Biomarkers have improved health outcomes and led to accelerated drug approvals in key areas of unmet need such as oncology. Quantitative biomarker measures such as HbA1c a standard test for the monitoring of diabetes has impacted patient care and management, both for the healthcare professionals and the patient community. Such advances accelerate opportunities for early intervention including prevention of disease in high-risk individuals. In PD, progression markers are needed at all stages of the disease in order to catalyze drug development — this allows interventions aimed to halt or slow disease progression (very early) but also facilitates symptomatic treatments at moderate stages of the disease. Recently, attention has turned to the role of digital health technologies to complement the traditional modalities as they are relatively low cost, objective and scalable. Success in this endeavor would be transformative for clinical research and therapeutic development. Consequently, significant investment has led to a number of collaborative efforts to identify and validate suitable digital biomarkers of disease progression.
\end{abstract}

Keywords: Parkinson's disease, digital health technologies, biomarkers, regulatory science, drug development, clinical research, collaborations

${ }^{*}$ Correspondence to: Diane Stephenson, PhD, Critical Path for Parkinson's Consortium, Critical Path Institute, 1730 E. River Rd., Tucson, AZ, 85718, USA. Tel.: +1 520382 1405; E-mail: dstephenson@c-path.org.

\begin{abstract}
AIMS
Here we aim to provide a perspective on the current state of digital biomarkers of disease progression
\end{abstract}


in clinical research and look to identify opportunities to advance this field forward in accelerated ways. We focus this review on biomarkers of motor progression because these are the most mature, but recognize the wider opportunity is to expand to symptom domains such as cognitive impairment that impact Quality of Life and overall health outcomes. In addressing the future perspective, we ask: What would optimal or excellent look like? What is required to achieve this and by when? Because the opportunity for digital health technologies (DHTs) and digital biomarkers is broad, throughout, we integrate the perspective of diverse stakeholders.

\section{DHTS AS DISEASE PROGRESSION BIOMARKERS}

PD serves as a flagship disease for evaluating DHTs given some of the cardinal manifestations related to mobility and motor impairment are amenable to assessment from widely available commercial and research grade devices [1,2]. DHTs allow for remote, long-term monitoring of patients in naturalistic settings such as the home, which can be key to understanding the dynamic nature of the disease.

Traditionally, biomarkers have served as indicators of normal biological and pathogenic processes, or responses to an intervention [3], and those that can be measured by a validated DHT are therefore termed as digital biomarkers [4]. A comprehensive comparison between traditional biomarkers and digital biomarkers has recently been reviewed by illustrating both commonalities and differences [5]. In 2016, the FDA and NIH collaborated to achieve consensus on definitions of types of biomarkers (BEST framework [6]). Specific biomarker categories that were defined include diagnostic, monitoring, pharmacodynamics/response, predictive, prognostic, safety, and susceptibility/risk biomarkers, and reasonably likely surrogate and validated surrogate endpoints [7]. Such categories are applicable to biomarkers acquired using digital device technologies and this topic was the focus of a 2020 conference including multistakeholder groups [8]. The FDA emphasized that, while traditional biomarkers may not have direct meaning to patients as they do not describe how a patient feels, functions, or survives, they should be informed by what is relevant to patients [8]. Manta et al. [9] proposed a framework to guide development of DHTs with patient centricity at the core.
In the clinic, traditional biomarkers can be invasive, expensive, and only present a snapshot of the disease due to limited measurements at infrequent time intervals $[10,11]$ thus monitoring of disease progression is subjective and not patient specific. By contrast, development of non-invasive, sensitive digital biomarkers offers the opportunity to support monitoring of disease progression through capturing dynamic fluctuating symptoms at home in the patient's lived environment [12, 13]. Digital health technologies may also reduce patient and site burden and enable engagement of more diverse populations including rural environmental settings. Combining traditional biomarkers with digital technologies, termed as 'digital phenotyping' offers the opportunity to enable multi-model integration of clinical, behavioral and neurophysiological patient data in real life settings [14].

\section{CURRENT LANDSCAPE: WHERE ARE WE NOW?}

Existing work in the space of digital biomarkers in PD has mainly involved investigative pilot research studies. Table 1 outlines a list of representative examples of ongoing observational studies aimed at advancing the field of PD digital progression biomarkers. These studies were selected as they are designed to assess how DHTs perform relative to other assessments with the goal of monitoring disease progression.

The studies listed in Table 1 are representative examples of single and multisite global clinical noninterventional studies which are important natural history investigations for advancing the use of DHTs as progression markers. Data from natural history and patient registries will both add to our understanding of how diseases progress and develop over time, but also assist in the determination of the endpoints where a clinically meaningful difference can be determined. Individual cohort studies represent an essential step before deploying in clinical trials where there is greater uncertainty and more sources of variability.

Two distinctive biomarker strategies are highlighted in Table 1. The most common approach is to identify biomarker signatures based on clinical phenotypes. Another novel concept is to embark on an unbiased non-phenotype driven population-based approach [19]. Each of the observational studies have some commonalities in that they recruit subjects 
Table 1

Examples of biomarker-progression studies in PD

\begin{tabular}{|c|c|c|c|c|c|}
\hline & PPMI [3] & PPP [15] & CCBP [16] & WATCH-PD [17] & OPDC [18] \\
\hline Overview & $\begin{array}{l}\text { To identify } \\
\text { biomarkers of PD } \\
\text { progression }\end{array}$ & $\begin{array}{l}\text { To identify } \\
\text { biomarkers of PD } \\
\text { progression }\end{array}$ & $\begin{array}{l}\text { Reverse } \\
\text { biology-to-phenotype } \\
\text { biomarker } \\
\text { development to } \\
\text { investigate progression } \\
\text { of PD and other } \\
\text { neurodegenerative } \\
\text { diseases }\end{array}$ & $\begin{array}{l}\text { To elucidate digital } \\
\text { biomarkers of disease } \\
\text { progression and } \\
\text { response to } \\
\text { symptomatic } \\
\text { treatment. }\end{array}$ & $\begin{array}{l}\text { To identify baseline } \\
\text { digital } \\
\text { technologies that } \\
\text { distinguish motor } \\
\text { progression in } \\
\text { iRBD vs PD vs } \\
\text { Controls }\end{array}$ \\
\hline $\begin{array}{l}\text { Biomarker } \\
\text { type }\end{array}$ & Disease progression & Disease progression & Sub-typing & Disease progression & $\begin{array}{l}\text { Progression in at risk } \\
\text { individuals (RBD) }\end{array}$ \\
\hline $\begin{array}{l}\text { Directionality } \\
\text { of analysis }\end{array}$ & $\begin{array}{l}\text { phenotype to } \\
\text { biomarker }\end{array}$ & $\begin{array}{c}\text { phenotype to } \\
\text { biomarker }\end{array}$ & $\begin{array}{l}\text { (bioassay-based) } \\
\text { biomarker to (digital) } \\
\text { phenotype }\end{array}$ & phenotype to biomarker & $\begin{array}{l}\text { phenotype to } \\
\text { biomarker }\end{array}$ \\
\hline PD stage & $\mathrm{PD} \leq 2$ years & $\mathrm{PD} \leq 5$ years & $\begin{array}{l}\text { PD, PD-like, AD, } \\
\text { AD-like (inclusive, } \\
\text { any disease stage) }\end{array}$ & $\mathrm{PD} \leq 2$ years & $\mathrm{PD} \leq 3.5$ years \\
\hline Enrolment & $\begin{array}{l}400 \mathrm{PD}(1400 \\
\text { subjects) } 200 \mathrm{HC}\end{array}$ & $650 \mathrm{PD} 0 \mathrm{HC}$ & $\begin{array}{l}4000 \text { PD, PD-like, AD, } \\
\text { AD-like patients } 1000 \\
\text { HC }\end{array}$ & $100 \mathrm{PD} 50 \mathrm{HC}$ & $\begin{array}{l}334 \mathrm{PD} \\
84 \mathrm{HC} \\
104 \mathrm{iRBD}\end{array}$ \\
\hline Device type & $\begin{array}{l}\text { Smartwatch: } \\
\text { accelerometer } \\
\text { data, pulse rate, } \\
\text { ECG }\end{array}$ & $\begin{array}{l}\text { Smartwatch: } \\
\text { accelerometer } \\
\text { data, pulse rate, } \\
\text { ECG, clinical } \\
\text { scales, and } \\
\text { questionnaires }\end{array}$ & $\begin{array}{l}\text { Smartwatch: pulse rate, } \\
\text { HRV, sleep-related } \\
\text { parameters }\end{array}$ & $\begin{array}{l}\text { Smartwatch and } \\
\text { smartphone (custom } \\
\text { app): continuous } \\
\text { passive monitoring, } \\
\text { ePRO, cognitive and } \\
\text { motor tests }\end{array}$ & $\begin{array}{l}\text { Smartphone: } \\
\text { accelerometer, } \\
\text { microphone, and } \\
\text { touch screen }\end{array}$ \\
\hline $\begin{array}{l}\text { At home } \\
\text { assessment }\end{array}$ & $\begin{array}{l}\text { Smartwatch } \\
\text { monitoring }\end{array}$ & $\begin{array}{l}\text { Smartwatch passive } \\
\text { monitoring: } \\
22 \text { h/day, 2-years }\end{array}$ & $\begin{array}{l}\text { Smartwatch passive } \\
\text { monitoring: } 24-h \\
\text { continuous data }\end{array}$ & $\begin{array}{l}\text { Smartwatch and } \\
\text { smartphone passive } \\
\text { and active monitoring } \\
\text { Smartphone active } \\
\text { tests: Structured } \\
\text { 15-min mobile } \\
\text { assessment battery } \\
\text { consisting of ePRO, } \\
\text { cognitive and motor } \\
\text { tests }\end{array}$ & $\begin{array}{l}\text { Smartphone active } \\
\text { tests: Voice, } \\
\text { balance, gait, } \\
\text { finger tapping, } \\
\text { reaction time, rest } \\
\text { tremor, and } \\
\text { postural tremor }\end{array}$ \\
\hline $\begin{array}{l}\text { Accessibility } \\
\text { to data }\end{array}$ & $\begin{array}{l}\text { Study data publicly } \\
\text { available to } \\
\text { research } \\
\text { community }\end{array}$ & $\begin{array}{l}\text { Study data publicly } \\
\text { available to } \\
\text { research } \\
\text { community }\end{array}$ & $\begin{array}{l}\text { Study data publicly } \\
\text { available to research } \\
\text { community }\end{array}$ & $\begin{array}{l}\text { Data available to CPP } \\
\text { Consortium members } \\
\text { of 3DT project }\end{array}$ & $\begin{array}{l}\text { On request to OPDC } \\
\text { steering committee }\end{array}$ \\
\hline
\end{tabular}

Comparison between ongoing biomarker-progression PD clinical studies. Here we list a subset of the most exhaustive studies, all of which are ongoing: PPMI, Parkinson's Progression Markers Initiative; PPP, Personalized Parkinson Project; CCBP, Cincinnati Cohort Biomarker Program; WATCH-PD, Wearable Assessments in the Clinic and Home in PD, OPDC, Oxford Parkinson's Disease Discovery Cohort; PD, Parkinson's disease; iRBD, idiopathic REM sleep behavior disorder; AD, Alzheimer disease; HC, healthy controls; ePRO, electronic patient reported outcomes; ECG, electrocardiogram; HRV, heart rate variability.

at a relatively early stage and they evaluate DHT tools in conjunction with other assessments. Several differences emerge when evaluating the studies in greater detail including selection of digital device platform, specific symptom domains or concepts of interest, duration of study, sample size, and investigation of non-PD subjects in parallel. As all studies are still ongoing; as such, learnings will evolve as data emerges. Large amounts of data from the above studies can be used for advanced analytics approaches (Artificial Intelligence/Machine Learning), potentially to expand on traditional outcomes, although the diversity of variables in the different studies will make it challenging to integrate or harmonize data beyond one study at a time.

\section{Existing gaps}

Despite the promising outlook of digital biomarkers in research, it is important to bridge the following gaps to facilitate their adoption in practice and deliver patients the best care they deserve.

1 Limited attention to aligning with patientcentered outcomes: Concepts being measured 
often focus on motor manifestations of the disease given such symptoms are most amenable to measurement using DHTs as highlighted in Table 1. Yet, non-motor symptoms are reported to be very burdensome to people living with PD $[20,21]$.

2 Lack of collaborations: Individual studies are generally underpowered to measure significant changes in a slowly progressive degenerative heterogeneous disease, providing an incomplete picture of the specific data attributes collected from diverse patient cohorts.

3 Lack of data standards and harmonization: Different approaches and the lack of consensus on data standards for data collection has resulted in the inability to harmonize data collected from distinct/different devices. This consequently hinders data integration for meta-analysis and results in duplication of effort.

4 Lack of consensus on analytical and clinical validation: Challenges remain in validating digital biomarkers extracted by machine learning algorithms in uncontrolled settings, especially when gold standard references are not considered optimal [22]. For example, in the Fox insight study [23], it was found that mowing the lawn mimicked tremor in the sensor data collected at home.

5 Lack of open science and data sharing: Concerns and barriers posed by key stakeholders for intellectual property (IP) and competition hinders data sharing and synergy of efforts. Black box algorithms from individual device manufacturers strategies related to IP pose barriers for assuring complete provenance and reliability of data workstreams.

The truth is that there is a large gulf that still remains between promise and practice. Many reviews have highlighted the challenges that exist in this rapidly evolving area with special focus on PD [24-29].

Given that previous attempts to identify disease progression biomarkers have yet to succeed - can we be confident that digital biomarkers will prevail? Can we justify the investment, effort and burden on patients who willingly participate in observational studies when no experimental treatment is being evaluated? We look forward by sharing visionary perspectives and focus on key areas where change is needed.

\section{FUTURE LANDSCAPE: WHERE DO WE NEED TO BE?}

\section{Patient focus}

The voice of people living with PD needs to be front and center at all stages of development from identification of concepts of interest to the final patient interviews for every study. It is important to focus on symptoms manifestation across all stages of the disease spectrum, as patients are often interested in capturing and managing complex signs and burdensome features. Patients expect user-friendly DHTs with minimal burden. DHTs that do not reflect this will ultimately suffer from poor patient adherence, negatively impacting the value of the data.

\section{Collaborations}

Aligning global efforts is key to gain efficiencies, embrace open science and foster broad collaborations to avoid duplication and save time and resources. Precompetitive public private partnerships such as the European Innovative Medicines Initiative Programs IDEA-FAST [30] and Mobilise-D [31, 32] and the Critical Path's for Parkinson's Consortium [33] of the Critical Path Institute, promise to address gaps in the development of DHTs by engaging in multi-stakeholder collaborations. In these initiatives, the inclusion of technology experts, engineers, patient advocacy organizations, clinicians, patients, epidemiologists, health authorities and industry stakeholders is key to success.

\section{Data standardization}

The development of data and metadata standards are urgently needed to harmonize structured data collection and well-defined definitions of the data. Metadata, i.e., data that accompany and describe the primary data, can be utilized to better understand the context of the sensor data, such as specifying the symptom probing task undertaken by a patient, or the location of the digital health technology on the patient's body. Data and metadata standards will play an important role in facilitating data harmonization as they will allow us to articulate and specify the information required to create comparable and integrable datasets. Progress in advancing this area has been initiated as supported by the Michael J Fox Foundation and multistakeholders who collaboratively proposed a metadata framework with PD digital biomarkers as the center of focus [34]. 


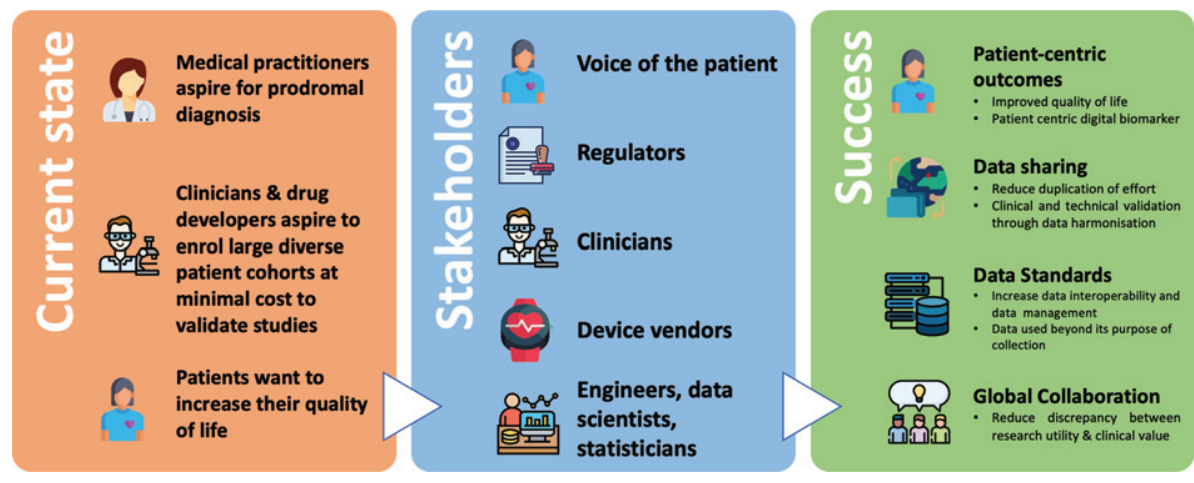

Fig. 1. Digital Biomarkers for Parkinson's Disease: Opportunities for the future. An overview of the current state of digital biomarkers for $\mathrm{PD}$, and what success can be achieved by bringing all key stakeholders to collaborate together.

\section{Advanced analytics and rigor}

As patient monitoring outside the lab is more likely to provide significant value in clinical decisionmaking and clinical trials, it will be important to perform quality control to strip the data of confounding factors in the environment that may generate misleading results [34]. Thus, analytical and clinical validation of digital biomarkers is necessary to ensure that clinical and healthcare decisions are not at scrutiny if machine learning algorithms fail to work as intended [5, 35].

\section{Data sharing and open science}

The majority of people living with PD want to assure that data based on the lived experience can be shared [36-38]. As expressed by patients, "Data sharing, especially for Parkinson's where there are no effective treatments, is critical. Science is a community, continually building on each other's ideas. In the era of electronic knowledge exchange, only when data sharing becomes the norm, can we derive its full benefits" [39]. A precedent for patient consent to data sharing took place with the mPower study where more than 10,000 people with Parkinson's agreed to share data directly at the time they signed onto the PD app [40]. Open source platforms that have the potential to work with different propriety algorithms would be a catalyst to advancing this area.

Finally, it is recommended that a diversity of biomarker strategies is pursued including both clinical phenotype-driven and unbiased non-phenotype driven population-based approaches with the goal of analyzing progression using a multidomain strategy as opposed to relying on a single biomarker.
Figure 1 illustrates a potential roadmap outlining current and future visions for this rapidly evolving space.

\section{SUMMARY}

The landscape of digital biomarkers in PD is one that is rapidly evolving, yet it is a field that has been ongoing for nearly a decade. Why is it taking so long? People suffering from the relentless progression and burden of PD do not have time to wait. So, what can be done now and why is it the right time to transform and elicit change? One of the unintended consequences of the Coronavirus pandemic is the rapid advancement of remote monitoring technologies [41]. When witnessing the speed that such transformations have taken place in a matter of months, it's clear that the time is now to apply such innovative strategies to rapidly moving the field of Parkinson's digital tools forward. It is time we pay attention to the hidden pandemic of PD [42] and work collaboratively around the world to make change happen with utmost speed and a sense of urgency.

\section{ACKNOWLEDGMENTS}

The authors thank Kimberly Ward Barowicz for support in preparation of the manuscript. CPP acknowledges the members of the CPP consortium, its scientific advisors, the CPP digital drug development tool team (3DT) and Parkinson's UK. D. Stephenson acknowledges the staff of the U.S. FDA's Office of Neuroscience staff for dedication to expanding the role of the voice of the patient in drug development. The authors graciously acknowledge the role of brave people living with Parkinson's in shaping this perspective. 


\section{CONFLICT OF INTEREST}

The authors declare that they do not have any financial or personal relationships with other people or organizations that could have inappropriately influenced this paper.

\section{REFERENCES}

[1] Rovini E, Maremmani C, Cavallo F (2017) How wearable sensors can support Parkinson's disease diagnosis and treatment: A systematic review. Front Neurosci 11, 555.

[2] Hansen C, Sanchez-Ferro A, Maetzler W (2018) How mobile health technology and electronic health records will change care of patients with Parkinson's disease. J Parkinsons Dis 8, S41-S45.

[3] Biomarkers Definitions Working Group (2001) Biomarkers and surrogate endpoints: Preferred definitions and conceptual framework. Clin Pharmacol Ther 69, 89-95.

[4] Coravos A, Khozin S, Mandl KD (2019) Developing and adopting safe and effective digital biomarkers to improve patient outcomes. NPJ Digit Med 2, 1-5.

[5] Goldsack JC, Coravos A, Bakker JP, Bent B, Dowling AV, Fitzer-Attas C, Godfrey A, Godino JG, Gujar N, Izmailova E, Manta C, Peterson B, Vandendriessche B, Wood WA, Wang KW, Dunn J (2020) Verification, analytical validation, and clinical validation (V3): The foundation of determining fit-for-purpose for Biometric Monitoring Technologies (BioMeTs). NPJ Digit Med 3, 55.

[6] FDA-NIH Biomarker Working Group (2016) BEST (Biomarkers, EndpointS, and other Tools) Resource, Food and Drug Administration (US), Silver Spring (MD). https:// www.ncbi.nlm.nih.gov/books/NBK338449/, updated September 25, 2017.

[7] Califf RM (2018) Biomarker definitions and their applications. Exp Biol Med 243, 213-221.

[8] Izmailova ES, Wagner JA, Ammour N, Amondikar N, BellVlasov A, Berman S, Bloomfield D, Brady LS, Cai X, Calle RA, Campbell M, Cerreta F, Clay I, Foschini L, Furlong P, Goldel R, Goldsack JS, Groenen PMA, Folarin A, Heemskerk J, Honig P, Hotopf M, Kamphaus T, Karlin DR, Leptak C, Liu Q, Manji H, Mather RJ, Menetski JP, Narayan VA, Papadopoulos E, Patel B, Patrick-Lake B, Podichetty JT, Pratap A, Servais L, Stephenson D, Tenaerts $\mathrm{P}$, Tromberg BJ, Usdin S, Vasudevan S, Zipunnikov V, Hoffmann SC (2020) Remote digital monitoring for medical product development. Clin Transl Sci, doi: 10.1111/cts. 12851

[9] Manta C, Patrick-Lake B, Goldsack JC (2020) Digital measures that matter to patients: A framework to guide the selection and development of digital measures of health. Digit Biomark 4, 69-77.

[10] Dunn J, Runge R, Snyder M (2018) Wearables and the medical revolution. Pers Med 15, 429-448.

[11] Babrak LM, Menetski J, Rebhan M, Nisato G, Zinggeler M, Brasier N, Baerenfaller K, Brenzikofer T, Baltzer L, Vogler C, Gschwind L, Schneider C, Streiff F, Groenen PMA, Miho E (2019) Traditional and digital biomarkers: Two worlds apart? Digit Biomark 3, 92-102.

[12] Gold M, Amatniek J, Carrillo MC, Cedarbaum JM, Hendrix JA, Miller BB, Robillard JM, Rice JJ, Soares H, Tome MB, Tarnanas I, Vargas G, Bain LJ, Czaja SJ (2018) Digital technologies as biomarkers, clinical outcomes assessment, and recruitment tools in Alzheimer's disease clinical trials. Alzheimers Dement (N Y) 4, 234-242.

[13] Dorsey ER, Papapetropoulos S, Xiong M, Kieburtz K (2017) The first frontier: Digital biomarkers for neurodegenerative disorders. Digit Biomark 1, 6-13.

[14] Smith DG (2018) Digital phenotyping approaches and mobile devices enhance CNS biopharmaceutical research and development. Neuropsychopharmacology 43, 25042505.

[15] Bloem BR, Marks WJ, Silva de Lima AL, Kuijf ML, van Laar T, Jacobs BPF, Verbeek MM, Helmich RC, van de Warrenburg BP, Evers LJW, intHout J, van de Zande T, Snyder TM, Kapur R, Meinders MJ (2019) The Personalized Parkinson Project: Examining disease progression through broad biomarkers in early Parkinson's disease. BMC Neurol 19, 160.

[16] Sturchio A, Marsili L, Vizcarra JA, Dwivedi AK, Kauffman MA, Duker AP, Lu P, Pauciulo MW, Wissel BD, Hill EJ, Stecher B, Keeling EG, Vagal AS, Wang L, Haslam DB, Robson MJ, Tanner CM, Hagey DW, El Andaloussi S, Ezzat K, Fleming RMT, Lu LJ, Little MA, Espay AJ (2020) Phenotype-agnostic molecular subtyping of neurodegenerative disorders: The Cincinnati Cohort Biomarker Program (CCBP). Front Aging Neurosci 12, 324.

[17] Adams JL (2020) WATCH-PD: Wearable assessments in the clinic and home in Parkinson's disease: Study design and update. Mov Disord 35, S1-S702.

[18] Lawton M, Baig F, Rolinski M, Ruffman C, Nithi K, May MT, Ben-Shlomo Y, Hu MTM (2015) Parkinson's disease subtypes in the Oxford Parkinson Disease Centre (OPDC) discovery cohort. J Parkinsons Dis 5, 269-279.

[19] Espay AJ, Schwarzschild MA, Tanner CM, Fernandez HH, Simon DK, Leverenz JB, Merola A, Chen-Plotkin A, Brundin P, Kauffman MA, Erro R, Kieburtz K, Woo D, Macklin EA, Standaert DG, Lang AE (2017) Biomarkerdriven phenotyping in Parkinson's disease: A translational missing link in disease-modifying clinical trials. Mov Disord 32, 319-324.

[20] Hermanowicz N, Jones SA, Hauser RA (2019) Impact of non-motor symptoms in Parkinson's disease: A PMDAlliance survey. Neuropsychiatr Dis Treat 15, 2205-2212.

[21] Andrejack J, Mathur S (2020) What people with Parkinson's disease want. J Parkinsons Dis 10, S5-S10.

[22] Evers LJW, Krijthe JH, Meinders MJ, Bloem BR, Heskes TM (2019) Measuring Parkinson's disease over time: The real-world within-subject reliability of the MDS-UPDRS. Mov Disord 34, 1480-1487.

[23] Smolensky L, Amondikar N, Crawford K, Neu S, Kopil CM, Daeschler M, Riley L, 23andMe Research Team, Brown E, Toga AW, Tanner C (2020) Fox Insight collects online, longitudinal patient-reported outcomes and genetic data on Parkinson's disease. Sci Data 7, 67.

[24] Espay AJ, Bonato P, Nahab F, Maetzler W, Dean JM, Klucken J, Eskofier BM, Merola A, Horak F, Lang AE, Reilmann R, Giuffrida J, Nieuwboer A, Horne M, Little MA, Litvan I, Simuni T, Dorsey ER, Burack MA, Kubota K, Kamondi A, Godinho C, Daneault J-F, Mitsi G, Krinke L, Hausdorff JM, Bloem BR, Papapetropoulos S (2016) Technology in Parkinson disease: Challenges and opportunities. Mov Disord 31, 1272-1282.

[25] Espay AJ, Hausdorff JM, Sánchez-Ferro Á, Klucken J, Merola A, Bonato P, Paul SS, Horak FB, Vizcarra JA, Mestre TA, Reilmann R, Nieuwboer A, Dorsey ER, Rochester L, Bloem BR, Maetzler W, Movement Disorder Society Task 
Force on Technology (2019) A roadmap for implementation of patient-centered digital outcome measures in Parkinson's disease obtained using mobile health technologies. Mov Disord 34, 657-663.

[26] Stephenson D, Alexander R, Aggarwal V, Badawy R, Bain L, Bhatnagar R, Bloem BR, Boroojerdi B, Burton J, Cedarbaum JM, Cosman J, Dexter DT, Dockendorf M, Dorsey ER, Dowling AV, Evers LJW, Fisher K, Frasier M, GarciaGancedo L, Goldsack JC, Hill D, Hitchcock J, Hu MT, Lawton MP, Lee SJ, Lindemann M, Marek K, Mehrotra N, Meinders MJ, Minchik M, Oliva L, Romero K, Roussos G, Rubens R, Sadar S, Scheeren J, Sengoku E, Simuni T, Stebbins G, Taylor KI, Yang B, Zach N, on behalf of the Critical Path for Parkinson's Consortium (2020) Precompetitive consensus building to facilitate the use of digital health technologies to support Parkinson disease drug development through regulatory science. Digit Biomark 4(suppl 1), 28-49.

[27] Guo C, Ashrafian H, Ghafur S, Fontana G, Gardner C, Prime M (2020) Challenges for the evaluation of digital health solutions-A call for innovative evidence generation approaches. NPJ Digit Med 3, 110.

[28] Mantua V, Arango C, Balabanov P, Butlen-Ducuing F (2020) Digital health technologies in clinical trials for central nervous system drugs: An EU regulatory perspective. Nat Rev Drug Discov, doi: 10.1038/d41573-020-00168-Z

[29] Mehta N, Wang J, Wang Y, Zhu H, Liu Q (2020) The use of mobile technology in drug development. Clin Pharmacol Ther 108, 706-709.

[30] IDEA-FAST - Identifying digital endpoints to assess fatigue, sleep and activities in daily living in neurodegenerative disorders and immune-mediated inflammatory diseases. https://idea-fast.eu/

[31] Rochester L, Mazzà C, Mueller A, Caulfield B, McCarthy M, Becker C, Miller R, Piraino P, Viceconti M, Dartee WP, Garcia-Aymerich J, Aydemir AA, Vereijken B, Arnera V, Ammour N, Jackson M, Hache T, Roubenoff R (2020) A roadmap to Inform Development, Validation and Approval of Digital Mobility Outcomes: The Mobilise-D approach. Digit Biomark 4(Suppl 1), 13-27.

[32] Viceconti M, Hernandez Penna S, Dartee W, Mazzà C, Caulfield B, Becker C, Maetzler W, Garcia-Aymerich J, Davico G, Rochester L (2020) Toward a regulatory qualification of real-world mobility performance biomarkers in
Parkinson's patients using digital mobility outcomes. Sensors 20, 5920.

[33] Stephenson D, Hu MT, Romero K, Breen K, Burn D, BenShlomo Y, Bhattaram A, Isaac M, Venuto C, Kubota K, Little MA, Friend S, Lovestone S, Morris HR, Grosset D, Sutherland M, Gallacher J, Williams-Gray C, Bain LJ, Avilés E, Marek K, Toga AW, Stark Y, Forrest Gordon M, Ford S (2015) Precompetitive data sharing as a catalyst to address unmet needs in Parkinson's disease. J Parkinsons Dis 5, 581-594.

[34] Badawy R, Hameed F, Bataille L, Little MA, Claes K, Saria S, Cedarbaum JM, Stephenson D, Neville J, Maetzler W, Espay AJ, Bloem BR, Simuni T, Karlin DR (2019) Metadata concepts for advancing the use of digital health technologies in clinical research. Digit Biomark 3, 116-132.

[35] Liu Q, Zhu H, Liu C, Jean D, Huang S-M, ElZarrad MK, Blumenthal G, Wang Y (2020) Application of machine learning in drug development and regulation: Current status and future potential. Clin Pharmacol Ther 107, 726-729.

[36] Frasier M (2016) Perspective: Data sharing for discovery. Nature 538, S4.

[37] Port R, Rumsby M, Brown G, Harrison IF, Amjad A, Bale CJ (2021) People with Parkinson's: What symptoms do they most want to improve and how does this change with disease duration? J Parkinsons Dis, doi: 10.3233/JPD-202346.

[38] Institute of Medicine (2015) Sharing Clinical Trial Data: Maximizing Benefits, Minimizing Risk. The National Academies Press, Washington, DC. https://doi.org/10.17226/ 18998.

[39] Dubman S (2016) Call to Action: Sharing of Patient-Level Data for Parkinson's Research and Care. J Parkinsons Dis Blog, https://www.journalofparkinsonsdisease.com/blog/ guest-blog/call-action-sharing-patient-level-dataparkinson \%E2\%80\%99s-research-and-care.

[40] Bot BM, Suver C, Neto EC, Kellen M, Klein A, Bare C, Doerr M, Pratap A, Wilbanks J, Dorsey ER, Friend SH, Trister AD (2016) The mPower study, Parkinson disease mobile data collected using ResearchKit. Sci Data 3, 160011.

[41] Ting DSW, Carin L, Dzau V, Wong TY (2020) Digital technology and COVID-19. Nat Med 26, 459-461.

[42] Dorsey ER, Sherer T, Okun MS, Bloem BR (2018) The emerging evidence of the Parkinson pandemic. J Parkinsons Dis 8, S3-S8. 